\title{
THE EFFECT OF POSTURE UPON THE VELOCITY OF BLOOD FLOW IN MAN
}

\author{
BY WILLARD OWEN THOMPSON,1 JOSEPH M. ALPER, AND \\ PHEBE K. THOMPSON ${ }^{2}$
}

(From the Metabolism Laboratory of the Massachusetts General Hospital)

(Received for publication February 20, 1928)

\section{INTRODUCTION}

We (1) (2) have observed that a much longer time elapses in the standing still position than in the recumbent position before an intravenously injected dye attains a uniform concentration in the blood throughout the body. Measurements of the velocity of blood flow in different positions of the body have now been made by a dye method.

\section{METHOD}

The experiments were done in either the morning or early afternoon, with the subjects fasting. All experiments were preceded by a rest period of at least 30 minutes in the horizontal position. When in the upright position the subjects stood with their feet about 6 inches apart and remained as motionless as possible. About 2.5 to $3.0 \mathrm{cc}$. of a 4 to 5 per cent solution of brilliant vital red was quickly injected into a cubital vein or into a foot vein (usually the internal saphenous just below the internal malleolus). This amount of dye produced a well marked coloring of the serum and its injection rarely required more than 5 seconds. In the standing still position, the arm was held horizontally when dye was injected and down by the side when blood was collected.

In order to determine the time of the appearance of dye in the venous blood of any part of the body, venous blood from that part was collected in small test tubes which were changed at 15 second

${ }^{1}$ Fellow of the National Research Council. Research Fellow in Medicine, Harvard Medical School and Massachusetts General Hospital.

2 Research Fellow in Medicine, Massachusetts General Hospital. 


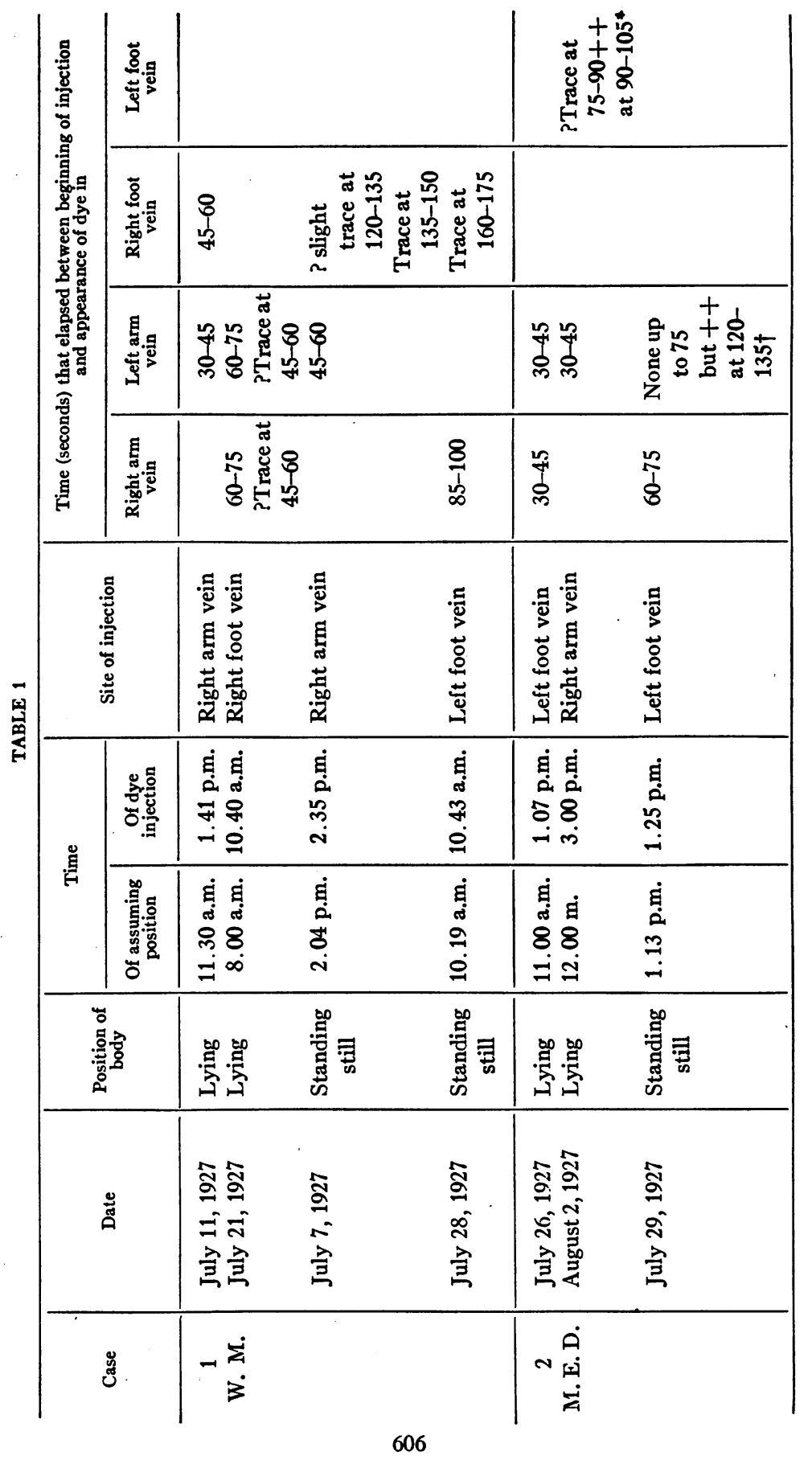




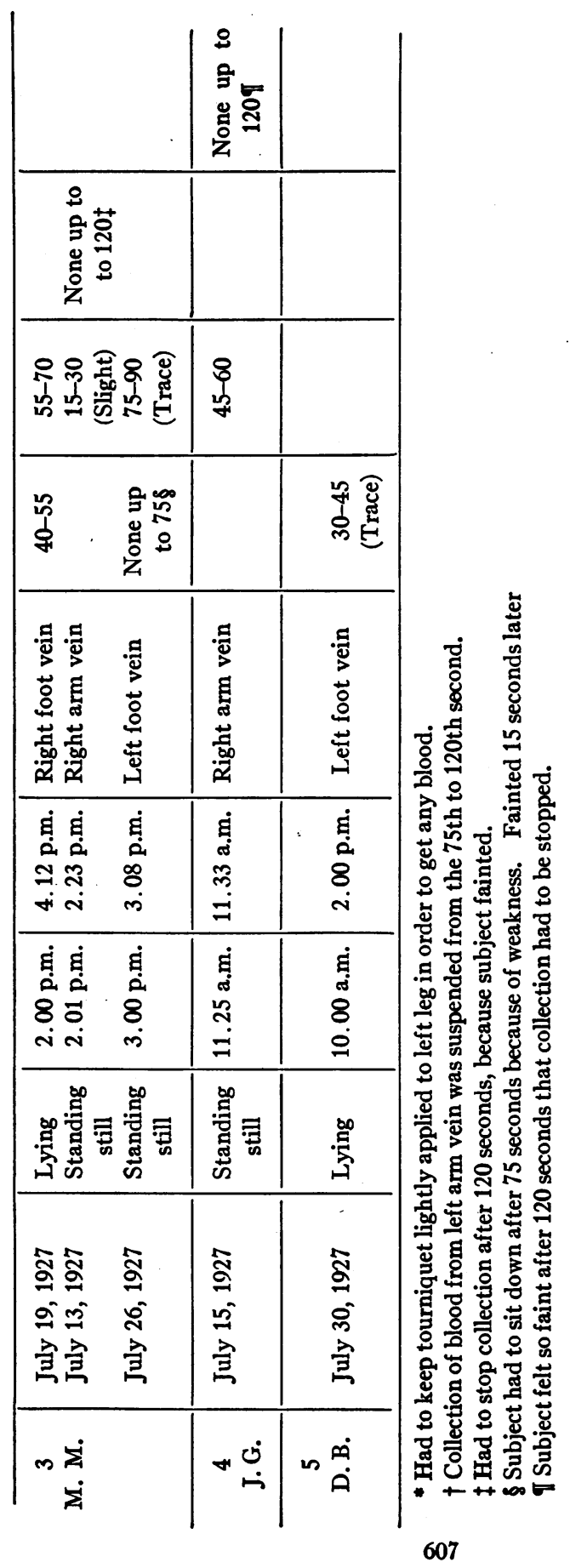


intervals, starting from the time of the beginning of the injection. The blood thus collected was allowed to clot in an ice chest and was then centrifuged. The presence of dye was detected by the color of the serum.

The arm to arm circulation time for the recumbent position found by this method is longer than that reported by Blumgart and his coworkers (3). This difference can probably be accounted for by the fact that in Blumgart's method (4):

1. The injection time is shorter.

2. The distance travelled is shorter (vein to artery instead of vein to vein).

3. The recording apparatus is sensitive enough to detect the first particle of radium $C$ that arrives within its field, whereas in our method a small amount of dye probably appears in the blood a few seconds before its concentration becomes great enough to cause a perceptible coloring of the serum.

The method we have used is, of course, a rough one but is accurate enough to show marked changes.

\section{EXPERIMENTAL RESULTS}

The data are summarized in table 1 . They show two significant things:

1. A much longer time is required for the dye to travel from a foot vein to an arm vein or the reverse in the standing still position than in the recumbent position.

2. The application of a tourniquet to a lower extremity so as to produce a moderate increase in venous pressure, when the subject is in the recumbent position, appears to be just as effective as the standing still position in prolonging the appearance time of the dye.

When the subject is in the standing still position, the dye seems to take a longer time to go from an arm vein to a foot vein than in the reverse direction. Thus in cases 1, 3 and 4, more than 120 seconds elapsed in each instance before dye injected into an arm vein appeared in a foot vein (i.e., at least twice as long as in the recumbent position, and probably longer). In cases 1 and 3 , on the contrary, 85 to 100 and 75 to 90 seconds respectively elapsed before dye injected into a 
foot vein appeared in an arm vein (i.e., at least $1 \frac{1}{2}$ times as long as in the recumbent position). This result, if corroborated by further experiments, is difficult to explain satisfactorily at present.

Observations by several workers (5), (6), (7), (8), (9), have shown that, in the standing still position, blood circulates with difficulty and collects in dependent portions of the body, owing to the effect of gravity. Our findings are in harmony with these observations.

\section{CONCLUSION}

A much longer time is required for blood to move from an arm vein to a foot vein or the reverse when an individual is in the standing still position than when he is in the recumbent position.

\section{BIBLIOGRAPHY}

1. Thompson, W. O., Thompson, P. K., and Dailey, M. E., Proc. of the Nat. Acad. of Sciences, January, 1928. The Effect of Posture upon the Composition and Volume of the Blood in Man.

2. Thompson, W. O., Thompson, P. K., and Dailey, M. E., J. Clin. Invest., 1928, v, 573. The Effect of Posture upon the Composition and Volume of the Blood in Man (more detailed account than (1)).

3. Blumgart, H. L., and Weiss, S., J. Clin. Invest., 1927, iv, 15. Studies on the Velocity of Blood Flow. II. The Velocity of Blood Flow in Normal Resting Individuals, and a Critique of the Method Used.

4. Blumgart, H. L., and Yens, O. C., J. Clin. Invest., 1927, iv, 1. Studies on the Velocity of Blood Flow. I. The Method Utilized.

5. Piorry, P. A., Arch. Gén. de Méd., 1826, xii, 527. Recherches sur l'influence de la pesanteur sur le cours du sang; diagnostic de la syncope et de l'apoplexie, cause et traitement de la syncope.

6. Salathé, A., Trav. du lab. de M. Marey, 1877, p. 251. De l'anémie et de la congestion cérébrales provoquées mecaniquement chez les animaux, par l'attitude verticale ou par un mouvement giratoire.

7. Hill, L., J. Physiol., 1895, xviii, 15. The Influence of the Force of Gravity on the Circulation of the Blood.

8. Field, H., Jr., and Bock, A. V., J. Clin. Invest., 1925, ii, 67. Orthopnea and the Effect of Posture upon the Rate of Blood Flow.

9. Turner, A., Am. J. Physiol., 1927, Ixxx, 601. The Circulatory Minute Volumes of Healthy Young Women in Reclining, Sitting and Standing Positions. 